\title{
The Study on Construction and Application Model of High-quality Resource Shared Courses in Chinese Colleges
}

\author{
Jie $\mathrm{Li}^{1,}$ a , Wanzhen $\mathrm{Li}^{1, \mathrm{~b}}$, Wanying $\mathrm{Qu}^{1, \mathrm{c}}$ and Ling Zhuang ${ }^{1, \mathrm{~d}}$ \\ ${ }^{1}$ College of Urban Construction, Wuhan University of Science and Technology, Wuhan 430065, \\ China \\ a15927628899@163.com, bqq3968@126.com, 'qwyhello@163.com, d1024245236@qq.com
}

Keywords: High-quality course; Resource sharing; Modern educational technology; Construction and application

\begin{abstract}
This paper studies the construction and application model of high-quality resource shared courses in Chinese colleges based on modern educational technology. Efforts should be made to improve the availability and usability of the online resources of high-quality courses, and realize the strategic shift from course construction to equal emphasis on construction and application, in this way to realize the original intention of high-quality course construction in colleges, realize resource sharing and improve the teaching quality. It is hoped that this can play a demonstration and leading role for other related course construction, which can provide result support and policy recommendation to the management.
\end{abstract}

\section{Introduction}

Entering the new century, how to promote fair education and improve educational quality by sharing high-quality resources has become a hotspot research issue in the Chinese educational field. In 2003, China initiated the national high-quality course construction program, and this program is an important component of China's higher education "quality project", which is a major educational and teaching reform program during the educational informationization process; as part of the global practice of educational resource development, the high-quality course construction has achieved significant effects, but there are also various problems, such as "focusing on report, sharing and evaluation, while ignoring construction, application and teaching", and "lack of effectiveness in network resource teaching". In 2011, the Ministry of Education decided to implement the "National High-quality Open Course" program during the "Twelfth Five-year" period, and in the next 5 years, efforts would be made to organize various colleges and universities to construct 5000 high-quality resource shared courses. The shared courses are based on the original national high-quality courses, and through structural optimization, transformation, upgrade and level-by-level selection, a high-quality course resource joint construction and sharing system on various levels (national, provincial and college level), at various layers (college, higher vocational and online education) and involving various types [1].

\section{College High-quality Resource Shared Course Construction and Research Status Quo}

After several years' development, the open educational resource movement has won approval from many educators and learners in the international community, which has become a practice trend in the global higher education field. According to incomplete statistics, 26 countries have practiced in open sharing of educational resources in various forms, including the United States, China, Britain, France, the Netherlands and Vietnam. On the aspect of foreign resource construction, the most successful experience is the MITOCM program, and many online courses and courseware have been built in this program, which has provided successful experience for international college informationization resource construction. MITOCM (MIT Open Course Ware) started in April. 2001, which plans to produce the materials of more than 2000 courses used in the teaching practice of MIT into online 
courseware, and put it onto the Internet in batches, so that any learners around the world can learn high-quality foreign courses for free. The college has provided uniform format for all courses, the teacher of a subject only needs to select, determine and release the shared content without considering the backstage technology and webpage production. For the teachers, the open courses only require them to publicize their teaching materials and plan, and their main job is to organize the teaching plan. Some international organizations and institutions (such as the UNESCO, Organization for Economic Co-operation and Development, the World Bank and Commonwealth of Learning) as well as some foundations (such as the Andrew Mellon Foundation and Hewlentt Foundation) have encouraged and supported the efforts made by various countries in sharing the educational resources.

In China, the construction of shared courses is a national program planned by the Ministry of Education, and led by the educational administrative departments from top down. During the development process, the teachers have to played multiple roles, such as the "course developer", "technical controller" and "participant", and for them, this is not only the competition of knowledge reservation and teaching design ability, but also involves the competition of educational technology, such as the webpage design and development. In the meantime, the teachers also have interaction with the learners, which is an interactive and independent school network [2].

Many domestic researchers have never stopped studying the construction of high-quality resource shared courses, and in the meantime, they have also studied problems existing on various aspects, including the evaluation system, construction of shared resources, teaching staff, construction technology of shared resources and supervisory mechanism. However, in accordance with the current situation of shared course website, with low accessing rate, low content update rate, high resource consumption rate and low resource utilization rate, it will make you think: what is going wrong? In order to realize sustainable development of shared courses, continuous analysis, exploration, modification and improvement should be made to specific problems during practice [3].

\section{Problems Existing in the Construction of High-quality Resource Shared Courses in College}

The key to construct high-quality resource shared courses is to implement high-quality resource shared courses. However, various colleges tend to "focus on project approval and review, while ignoring share and utilization", which tends to affect the sustainable development high-quality resource shared courses and makes it difficult for these courses to carry out their actual effects. There are still many deficiencies in the construction of high-quality resource shared courses, which are specifically presented as:

The High-quality Course Database Emphasizes Package while Ignoring Innovation. There are very few independent and innovative resources of high-quality resource shared courses. In accordance with related investigation, nearly $20 \%$ of the students believed "the online resource does not help much in their study, and they are not willing to use it"; some students also reflected that the high-quality courses "have slow update, and there is nothing new"; some students also expressed that even though there are many options of online courseware, most are simply the electronic version of traditional teaching material, and there is not much appealing content.

The Construction of High-quality Resource Shared Courses Emphasizes Review while Ignoring Construction. When apply for the high-quality resource shared courses, some course teams have thoroughly studied the review indices, and they mainly focus on the package. After being selected, they fail to provide $10 \%$ annual update required for high-quality resource shared courses, and some colleges only focus on quantity while paying no attention to the later construction. Although the national high-quality course resource center releases the supervision of various high-quality courses online every month, it only ensures that this website can be visited without involving the construction situation [4].

The High-quality Resource Shared Courses Emphasize Report while Ignoring Application. In accordance with the investigation of high-quality online resource utilization conducted by Higher Education Research Institute of Shandong University: only 5\% of the responding students chosen the 
option of "Very familiar", 25\% chose "Relatively familiar", $46 \%$ chose "Have heard of it, but unfamiliar with it", and $24 \%$ chose "Do not know it at all". In accordance with the situation of using high-quality courses, the result of online investigation shows that only $6 \%$ of the students "Frequently use" the online resources of high-quality courses within and out of the college, $28 \%$ "Occasionally use it", $30 \%$ "Rarely use it", and $37 \%$ of the students "Never use it". Through investigation of the students who rarely or never used the online resources of high-quality courses, about $35 \%$ of answered that "they do not know the existence of high-quality courses", 29\% expressed that "they are busy in regular study, and they do not have the time to use it", and $26 \%$ of the students believed that "the website link is poor, which is not convenient for use".

The Sharing of Course Resources Emphasizes Radiation while Ignoring Interaction. Many people who construct or manage the national high-quality courses believe that as long as the website of national high-quality courses can be accessed, the resource can be shared. Many websites for national high-quality courses only provide the browsing, presentation and downloading functions, without the functions for the users to evaluate the resource or upload their own resource, and the administrator won't organize, optimize or update their own network resources on a regular basis [4].

If the above malpractice continues to grow, it will definitely bury the program of national high-quality course construction, and therefore, it is necessary to study and apply sustainable development of national high-quality courses. The Ministry of Education also has also realized this, and it is preparing to suspend application for national high-quality courses in the next few years, while focusing on improving the construction quality of approved national courses.

\section{Research and Application of College High-quality Course Construction and Application in the Era of Resource Sharing}

The construction of high-quality shared courses is a dynamic process, which should follow the principle of "high quality, openness and sharing", and it should be standard and regulated. The "high quality" of shared courses should be demonstrated on the aspects of course content, resource construction and teaching design. In particular, the advantages of modern educational technology should be carried out to improve the online availability and usability of high-quality resources, and realize strategic shift from course construction to equal emphasis on construction and application, in this way to realize the original intention of high-quality course construction in colleges, realize resource sharing and improve the teaching quality. It is mainly achieved on the following several aspects:

The Update and Share of the Online Resources and Contents of Courses. The Ministry of Education requires using the network to conduct teaching and management of high-quality courses, and the online educational resources should be open to share high-quality teaching resources. It is also required that various high-quality course resources should be updated in a timely manner, and the annual update rate should reach 10\%. During the construction, update, share and application should be conducted to realize sustainable development of high-quality resource shared courses. In addition, the information technology should be used to present the educational resources to the learners in an efficient and fast way, in this way to realize sharing in the maximum scale, so that it can make up for various problems commonly existing in teaching material, such as long cycle, simple form and failure to keep up with the pace of times development, and it can also realize the teaching model to organically combine the classroom and online teaching.

Research and Development of Electronic Teaching Material. he teaching material is knowledge carrier that reflects the teaching content and requirement, which is the basic tool for teaching and important guarantee to improve the teaching material. Professor Zhang Minrui from Xi'an University of Technology pointed it out that: "The teaching material is a silent teacher for the students, and a good teaching material is far better than an ordinary teacher. A great teaching material is as important to the cultivation of high-quality talents as a great teaching." However, with the development and application of modern educational technology based on modern educational theory 
and supported by the information technology, the teaching material has obtained fast development in higher education. How to development and select outstanding teaching material and effectively use the electronic teaching material and courseware has become an important issue facing us [5].

Research and Application of the Teaching Model that Combines the Classroom and Online Teaching. At present, the blending teaching method that integrates the complementary advantages between online and classroom teaching has become a common concern. Under the blending teaching model, the teacher can not only conduct teaching through online classroom, but also conduct teaching activities after class, such as preparing for the class, assigning homework, reviewing homework and answering question. In addition to classroom teaching, after the class, the students can also conduct various learning activities, such as independent online learning, doing homework online and asking question online. How to use this model in course teaching in order to carry out the leading role of teacher and satisfy the students' requirement of independent learning is one of the contents we study here. Through this blending teaching model, we wish to improve the students' initiation in learning, expand their learning horizon, study the characteristics of high acceptance to course teaching through network and improve the utilization rate for high-quality resources [6].

Research and Application of the Animation Effects Optimization of Teaching System. Because the students do not have actual experience and lack intuitive understanding of classes with strong theoretical and practical characteristics, by combining actual examples, we can use modern technical approaches to conduct classroom observation, optimize the animation effects of class, well combine learning and entertainment and promote the teaching activities.

\section{Summary}

In conclusion, the construction of high-quality resource shared courses can be regarded as a comprehensive systematic program, which combines the teaching principle, teaching staff, teaching content, teaching material construction, educational technology, teaching method and management system with improvement of teaching staff as the precondition, with construction of auxiliary teaching material with corresponding level, strong pertinence and adaptability as the core, with modernization of teaching content as the base, with modern information technology measure as the platform, with scientific management system as guarantee, and with promotion of teaching resource sharing as the principle. The review and selection of high-quality resource shared courses is not the end, but the starting point. How to promote the in-depth development of high-quality resource shared courses is a long-term difficult task, which requires everyone's efforts and exploration.

\section{Acknowledgements}

2014 university-level high-quality resource shared course "Building Construction" of Wuhan University of Science and Technology(No:Z2014006x), and 2015 teaching research program of Wuhan University of Science and Technology: result of "Study on Construction and Application Model of High-quality Resource Shared Courses in Colleges” (No:2015x034).

\section{References}

[1] J. W, M.Z. Liu and Z.T. Zhu: China Educational Technology, (2013) No.12, p.40-46.

[2] F.X. Zhou: Journal of Higher Education Research, (2010) No.9, p.108.

[3] Y. Zhang: China New Technologies and Products, (2010) No.1, p.243.

[4] Y.M. Wang: Liaoning Higher Vocational Technical Institute Journal, (2010) No.10, p.57-58.

[5] Q. Chen: China Township Enterprises Accounting, (2009) No.11, p.163-164.

[6] Q. Chen: Heilongjiang Researches on Higher Education, (2012) No.8, p.173-175. 